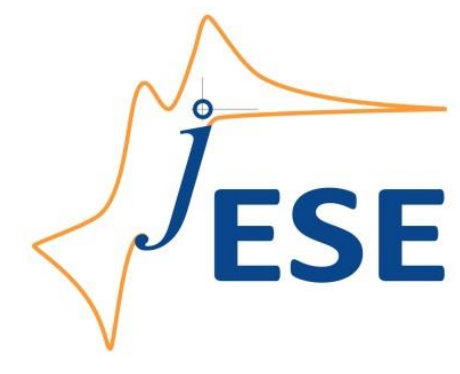

Open Access : : ISSN 1847-9286

www.jESE-online.org

Original scientific paper

\title{
Deposition efficiency in the preparation of ozone-producing nickel and antimony doped tin oxide anodes
}

\author{
Staffan Sandin ${ }^{1}$, Alicia Cheritat ${ }^{1}$, Joakim Bäckström ${ }^{2}$, Ann Cornell ${ }^{1, 凶}$ \\ ${ }^{1}$ Applied Electrochemistry, School of Chemical Science and Engineering, KTH Royal Institute of \\ Technology, Stockholm, Sweden \\ ${ }^{2}$ Department of Natural Sciences, Mid Sweden University, Sundsvall, Sweden
}

${ }^{\bowtie}$ Corresponding author: amco@kth.se

Received: February 8 2017; Revised: March 7, 2017; Accepted: March 13, 2017

\begin{abstract}
The influence of precursor salts in the synthesis of nickel and antimony doped tin oxide (NATO) electrodes using thermal decomposition from dissolved chloride salts was investigated. The salts investigated were $\mathrm{SnCl}_{4} \cdot 5 \mathrm{H}_{2} \mathrm{O}, \mathrm{SnCl}_{2} \cdot 2 \mathrm{H}_{2} \mathrm{O}, \mathrm{SbCl}_{3}$ and $\mathrm{NiCl}_{2} \cdot 6 \mathrm{H}_{2} \mathrm{O}$. It was shown that the use of $\mathrm{SnCl}_{4} \cdot 5 \mathrm{H}_{2} \mathrm{O}$ in the preparation process leads to a tin loss of more than $85 \%$. The loss of Sb can be as high as $90 \%$ while no indications of Ni loss was observed. As a consequence, the concentration of Ni in the NATO coating will be much higher than in the precursor solution. This high and uncontrolled loss of precursors during the preparation process will lead to an unpredictable composition in the NATO coating and will have negative economic and environmental effects. It was found that using $\mathrm{SnCl}_{2} \cdot 2 \mathrm{H}_{2} \mathrm{O}$ instead of $\mathrm{SnCl}_{4} \cdot 5 \mathrm{H}_{2} \mathrm{O}$ can reduce the tin loss to less than $50 \%$. This tin loss occurs at higher temperatures than when using $\mathrm{SnCl}_{4} \cdot 5 \mathrm{H}_{2} \mathrm{O}$ where the tin loss occurs from $56-147{ }^{\circ} \mathrm{C}$ causing the composition to change both during the drying $\left(80-110^{\circ} \mathrm{C}\right)$ and calcination $\left(460-550^{\circ} \mathrm{C}\right)$ steps of the preparation process. Electrodes coated with NATO based on the two different tin salts were investigated for morphology, composition, structure, and ozone electrocatalytic properties.
\end{abstract}

\section{Keywords}

NATO, ATO, tin chloride precursor, thermal decomposition, TGA, deposition, efficiency, dopant enrichment, ozone electrocatalysis

\section{Introduction}

The formation of ozone by electrolysis (reaction (1)) has been a topic of research for decades and many different anode materials such as $\mathrm{PbO}_{2}$ and boron doped diamond (BDD) have been investigated. A major problem to overcome is a low current efficiency for the desired ozone 
formation as $\mathrm{O}_{2}$ evolution is the dominating anode reaction in aqueous media. Current efficiencies of up to $50 \%[1,2]$ have been reached, but then requiring either low operational temperatures $\left(\mathrm{PbO}_{2}\right)[2,3]$, very high cell voltage (BDD) [4], or both [1]. This affects the overall efficiency resulting in a high-energy consumption, $65-84 \mathrm{kWh} / \mathrm{kg} \mathrm{O}$ and $130 \mathrm{kWh} / \mathrm{kg} \mathrm{O}$ for $\mathrm{PbO}_{2}$ [5,6] and $\mathrm{BDD}$ [1], respectively, to be compared with the energy consumption of the commercially common cold corona discharge (CCD) process of 8 - $29 \mathrm{kWh} / \mathrm{kg} \mathrm{O}_{3}$ [7].

$$
3 \mathrm{H}_{2} \mathrm{O} \rightarrow \mathrm{O}_{3}+6 \mathrm{H}^{+}+6 \mathrm{e}^{-} \quad E^{\circ}=1.51 \mathrm{~V} \text { vs. SHE }
$$

In 2004 a research group at The University of Hong Kong presented a new electrode coating for electrochemical ozone formation [8]. The ceramic coating was an antimony doped tin oxide (ATO) deposited on a titanium substrate showing very promising results for the formation of ozone (15\% current efficiency). In a later publication [9] the same group presented the discovery of trace amounts of nickel in their ATO coatings. On this basis, they continued the work on the nickel and antimony doped tin oxide (NATO) electrode [9]. An intriguing aspect of the material was that a very small concentration of nickel added to the mixed oxide yielded an electrode that made it possible to produce ozone at low anode potentials $(2.2 \mathrm{~V} \mathrm{vs}$. $\mathrm{Ag} / \mathrm{AgCl})$ at room temperature and at relatively high current efficiencies ( $30 \%$ ) while the current efficiency was almost $0 \%$ in the absence of nickel. Since then, several groups have studied the material and current efficiencies of up to $54 \%$ at potentials below $3 \mathrm{~V}$ vs. $\mathrm{Ag} / \mathrm{AgCl}$ have been reported [7,10-16]. The minimum energy demand found so far is $18 \mathrm{kWh} / \mathrm{kg} \mathrm{O}_{3}$ [7] which, to our knowledge, is the lowest value reported for the electrochemical formation of ozone and is moreover low enough to compete with the CCD process. In addition, unlike CCD, it has the advantages that ozone produced is directly dissolved in water, that no nitrogen oxides are formed and no refined gas $\left(\mathrm{O}_{2}\right)$ is needed.

The technique used for preparation of the mixed oxide has been the same in most of the publications on NATO electrodes. The metal salts $\mathrm{SnCl}_{4} \cdot 5 \mathrm{H}_{2} \mathrm{O}, \mathrm{SbCl}_{3}$ and $\mathrm{NiCl}_{2} \cdot 6 \mathrm{H}_{2} \mathrm{O}$ were dissolved in alcohol to the molar ratios of 1000:(16-20):(2-6) (Sn:Sb:Ni) [7,9-13,15]. This precursor solution is then coated on a pre-treated titanium substrate (foil or mesh) by brush, dip or spray coating. The coated substrate is dried for $10-15$ minutes at $100-110^{\circ} \mathrm{C}$ followed by calcination for $10-30$ minutes at $460-550{ }^{\circ} \mathrm{C}$. This is repeated until a satisfactory loading of the oxide layer is achieved ( 7 -20 layers) followed by a final calcination for a longer period ( $\sim 1$ hour). The current efficiencies reported for the electrodes prepared in this fashion ranges from 24 to $54 \%$. The molar ratios mentioned are optimized for the generation of ozone (maximizing current efficiency) $[7,9,15]$.

The variation in current efficiencies in the above-mentioned studies can depend on a number of parameters such as number of applied layers [11,14], electrolyte type $[9,11,17]$ and concentration $[9,11]$, current densities and potentials [9,14], cell design [12], or calcination temperatures $[14,18]$. In the present study, we have focused on the importance of the $\mathrm{Sn}, \mathrm{Sb}$, and Ni precursor salts. The tin precursor used in all of the previously mentioned NATO studies is the volatile $\mathrm{SnCl}_{4} \cdot 5 \mathrm{H}_{2} \mathrm{O}$. The melting point for the hydrous salt is $56{ }^{\circ} \mathrm{C}$ [19] and the boiling point for the anhydrous salt is $114{ }^{\circ} \mathrm{C}$ [19]. This low boiling temperature will lead to loss of tin during the preparation process, as described briefly by Comninellis et al. [20] in a study concerning the problems in $\mathrm{DSA}^{\circledR}$ coating deposition by thermal decomposition. They reported the deposition efficiency for this salt ( $\eta_{\text {eff }}=$ moles of tin after heating / moles of tin added) to be $21 \%$ when dissolved in the commonly used solvent ethanol. The boiling temperature of $\mathrm{SnCl}_{4}$ is very close to the drying temperature chosen in the studies previously described and it is therefore likely that tin is lost during both drying and calcination steps of the electrode preparation. As a consequence of this loss, the 
composition of the oxide coating will differ from the composition in the precursor solution. Since the tin loss occurs in both heating steps, the composition in the electrode coating and consequently its properties will be very sensitive to the choice of temperatures and duration of the two heating steps. This most probably leads to difficulties in controlling the resulting composition in the oxide coating which will have a negative effect on the reproducibility of the samples. The properties of antimony doped tin oxide anodes prepared in this fashion have indeed been shown to be very sensitive to the choice of temperature and duration during both drying and calcination $[14,21,22]$. As mentioned earlier, the optimized compositions (and maximum current efficiencies) determined for the NATO electrode coatings varies among studies. Although very few of the reviewed articles concerning the NATO electrodes have presented any data on sample reproducibility, Christensen et al. [7] reported a variation of as much as $30 \%$ in current efficiency within the same batch of electrodes. One contributing reason for this is most probably the volatile nature of the tetravalent salt, leading to an uncontrolled loss of tin during the electrode preparation and consequently an enrichment of dopants.

The actual composition of these doped tin oxide coatings has proven difficult to determine $[9,13,14,18,23]$ using XPS (X-ray photoelectron spectroscopy) or EDX (Energy-dispersive $X$-ray analysis), probably due to low nickel concentrations and the overlap of the tin and antimony spectral lines. Some studies have however reported measured compositions of their oxide coatings: Cheng et al. [8] determined the Sn:Sb ratio of their coating to 7:1 using ICP-MS (inductively coupled plasma -mass spectrometry), far from the composition in the prepared precursor solution of 65:1. This was later discussed to be a consequence of surface enrichment of Sb [9, 14]. Other studies have also reported an enrichment of either $\mathrm{Sb}$ or $\mathrm{Ni}$, or both [24-26]. Most authors correlate this to surface enrichment. To our knowledge, the loss of precursor salts has not been discussed as a possible reason for the high dopant concentration. In addition to the difficulties in predicting the composition of the final coating, the high loss of tin also means that the coating process has to be repeated more times than would be necessary if a less volatile precursor salt were to be used. This results in a preparation process that is inefficient from a practical and economical, as well as an environmental perspective. A preparation process that can be made in such a way that the resulting anode coating composition can be controlled and reproduced is of utmost importance for the continued work on the understanding of the detailed reaction mechanisms on the NATO surface, as well as for industrial implementations.

The problems described above with the loss of tin during the preparation process have, to our knowledge, not yet been considered in the published works concerning the NATO electrodes. One reason for this could be the difficulty in determining the composition in the oxide layer as discussed above. To understand and mitigate the issue of the evaporating tin source, the preparation process was investigated using both the common tetravalent tin precursor $\mathrm{SnCl}_{4} \cdot 5 \mathrm{H}_{2} \mathrm{O}$ and an alternative precursor salt, the divalent $\mathrm{SnCl}_{2} \cdot 2 \mathrm{H}_{2} \mathrm{O}$. The divalent salt has been reported to have a deposition efficiency of $57 \%$ when dissolved in ethanol [20], and the boiling point for the anhydrous salt $\left(623^{\circ} \mathrm{C}\right)[19]$ is well separated from the preparation temperatures, so loss of tin in the form of $\mathrm{SnCl}_{2}$ will be avoided. The heating process was examined using TGDSC (coupled thermogravimetry and differential scanning calorimetry), and electrodes prepared using both precursor salts were investigated regarding morphology and composition. The ozone formation capabilities of the electrodes were also briefly tested. 


\section{Experimental}

The oxide formation process (i.e. heating of salts and solutions) was characterized using coupled TG-DSC (Netzsch STA $449 \mathrm{F3}$ ), from room temperature $\left(22-25^{\circ} \mathrm{C}\right.$ ) to $600{ }^{\circ} \mathrm{C}$ at a heating rate of $5 \mathrm{~K} / \mathrm{min}$ in dry air at atmospheric pressure. The structure and morphology of the coatings was examined using XRD (X-ray diffraction, Bruker D2 Phaser) and SEM (scanning electron microscopy, Hitachi S-4800). The composition of the coatings was analysed using XRF (X-ray fluorescence, Philips PW2400).

The electrodes were prepared as follows. Grade 2 (commercially pure) titanium discs, $0.5 \mathrm{~mm}$ in thickness and $59 \mathrm{~mm}$ in diameter, were first cleaned in an ultrasonic bath followed by rinsing in ethanol, pickling in $1 \% \mathrm{HF}$ for 2 minutes, and followed by another ultrasonic cleaning and ethanol rinsing. The clean substrates were then dried at $80{ }^{\circ} \mathrm{C}$ for 60 minutes. The precursor solutions were prepared by mixing solutions of the individual salts, $\mathrm{SnCl}_{4} \cdot 5 \mathrm{H}_{2} \mathrm{O}$ (pro analysi, Sigma-Aldrich), $\mathrm{SnCl}_{2} \cdot 2 \mathrm{H}_{2} \mathrm{O}$ (pro analysi, Merck), $\mathrm{SbCl}_{3}$ (ACS reagent, Sigma-Aldrich), and $\mathrm{NiCl}_{2} 6 \mathrm{H}_{2} \mathrm{O}$ (pro analysi, Merck) to appropriate compositions with a tin concentration of $1 \mathrm{M}$.

Ethanol (analytical grade $99.5 \%$, Solveco) or n-propanol (ACS reagent $\geq 99.5 \%$, Sigma-Aldrich) were used as solvents and $\mathrm{HCl}$ ( $37 \%$, Merck) was added to keep the salts in solution (when n-propanol was used as solvent). The precursor solutions were coated on the titanium discs using either spin coating (1500 rpm for $30 \mathrm{~s}$ ) or drip coating. The coated substrates were then dried at $80^{\circ} \mathrm{C}$ for 10 minutes followed by calcination at $500^{\circ} \mathrm{C}$ for 10 minutes. This coating process was repeated 5 or 7 times followed by a final calcination at $500{ }^{\circ} \mathrm{C}$ for 60 minutes.

Analysis of ozone selectivity on the NATO electrodes was made at room temperature in galvanostatic experiments in an undivided batch cell from which electrolyte $\left(0.1 \mathrm{M} \mathrm{H}_{2} \mathrm{SO}_{4}\right)$ samples were taken for concentration determination by UV-Vis absorption spectroscopy (Expedeon Versastat) in a $1 \mathrm{~cm}$ path length quartz glass cell. As the gas phase was not analysed for ozone, the calculated current efficiencies were probably underestimated.

A more specific description of the electrode preparation process and chemicals and instruments used can be found in the supplementary information.

\section{Results and discussion}

First the decomposition processes of the pure precursor salts $\mathrm{SnCl}_{4} \cdot 5 \mathrm{H}_{2} \mathrm{O}, \mathrm{SnCl}_{2} \cdot 2 \mathrm{H}_{2} \mathrm{O}, \mathrm{SbCl}_{3}$, and $\mathrm{NiCl}_{2} \cdot 6 \mathrm{H}_{2} \mathrm{O}$ were studied using TG-DSC. After that, electrode coatings of mixed $\mathrm{Sn}, \mathrm{Sb}$, and Ni oxides using the two different tin precursors were prepared and characterized regarding structure, morphology, and composition. Finally, the electrodes were briefly tested for ozone generation. Details of some of the results can, as referred to in the text, be found in the supplementary information.

TG-DSC of non-dissolved salts

$\underline{\mathrm{SnCl}} 4.5 \mathrm{H}_{2} \underline{\mathrm{O}}$

As can be seen in Figure 1, the mass of the tetravalent tin salt rapidly starts decreasing almost as soon as the heating is initiated and goes along three distinct steps as the temperature increases.

The first large mass loss is initiated by the melting of the hydrous salt at just above $50{ }^{\circ} \mathrm{C}$, seen as a sharp endothermic peak (A) in the DSC data plot. That this is indeed the melting of the salt is supported by the absence of any peaks at this temperature in the differentiated TG (DTG) data. This temperature is also well in agreement with the literature melting point value of $56{ }^{\circ} \mathrm{C}$ [19]. The second peak (B) in the DSC data covers the entire temperature range (room temperature $-106^{\circ} \mathrm{C}$ ) of the first mass loss step where $49 \%$ of the initial mass is lost. 


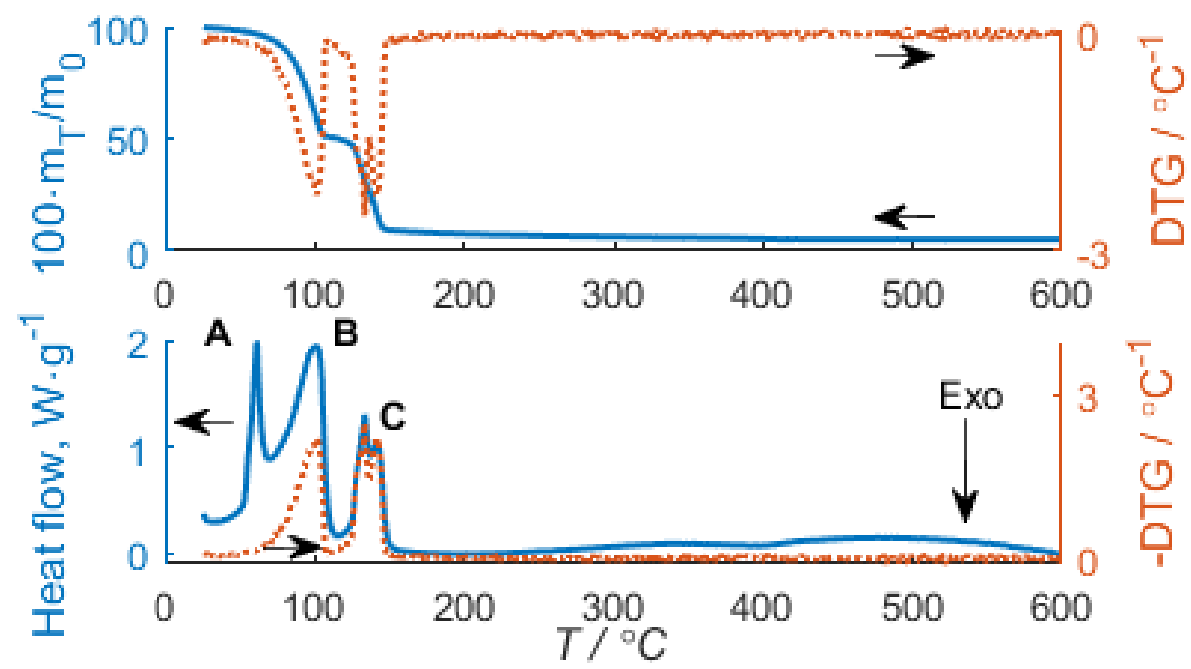

Figure 1. TG (upper) and DSC (lower) data plotted with the differentiated TG data (DTG) from heating of $\mathrm{SnCl}_{4} \cdot 5 \mathrm{H}_{2} \mathrm{O}$

The second mass loss step then continues up to approximately $147{ }^{\circ} \mathrm{C}$ during which another $41.5 \%$ of the mass is lost (double peak C in DSC data). This is followed by a slow mass loss up to approximately $410^{\circ} \mathrm{C}$ where $4.5 \%$ of the initial mass is lost. The mass stabilized at $5.2 \%$ of the initial mass, yielding a deposition efficiency $\left(\eta_{\text {eff }}\right)$ of $12 \%$ assuming that the end product is pure $\mathrm{SnO}_{2}$. Anhydrous $\mathrm{SnCl}_{4}$ has a melting point at $-33^{\circ} \mathrm{C}$ and a boiling point at $114{ }^{\circ} \mathrm{C}$ [19]. This means that the vapor pressure above the molten salt will be very high as soon as it loses its water of crystallization. The first mass loss region $\left(106^{\circ} \mathrm{C}\right.$ ) therefore most probably corresponds to the evaporation of $\mathrm{SnCl}_{4}$ and of $\mathrm{H}_{2} \mathrm{O}$. However, the total loss of tin corresponds to a $65 \%$ mass loss assuming $\mathrm{SnCl}_{4}$ as the only evaporating tin specie and the mass loss in the first step is $49 \%$. There is therefore most likely a competing reaction to the evaporation processes forming a more stable intermediary of tin that reacts in several steps in the second and third mass loss region before finally ending up in the tin oxide state. The loss of chlorine as $\mathrm{Cl}_{2}$ or some oxychlorine is also occurring in the process. Tin oxychlorines could be the intermediates forming and evaporating during the heating, as discussed by others $[27,28]$ for the heating of the divalent tin salt $\mathrm{SnCl}_{2} \cdot 2 \mathrm{H}_{2} \mathrm{O}$.

\section{$\underline{\mathrm{SnCl}} 2 \cdot 2 \cdot 2 \mathrm{H}_{2} \mathrm{O}$}

As seen in Figure 2, the heating characteristics of $\mathrm{SnCl}_{2} \cdot 2 \mathrm{H}_{2} \mathrm{O}$ are very different from those of the tetravalent salt.

The first peak (A) in the DSC data corresponds to both the loss of water (seen also as mass loss in the TG data), as well as the melting of the hydrated salt at approximately $40{ }^{\circ} \mathrm{C}$. The melting temperature agrees well with its literature value of $37^{\circ} \mathrm{C}$ [19]. The second peak in the DSC data (B) is also accompanied by a loss in mass, and since the anhydrous salt does not melt until $247{ }^{\circ} \mathrm{C}$ [19] (peak C in DSC), this loss in mass is attributed to further evaporation of water. After the melting of the anhydrous salt there is an exothermic change in the DSC signal (D) followed by a large mass loss $(E)$, seen both in the DSC and TG data. The loss in mass ends abruptly with an exothermic peak in the DSC signal (F). The total amount of mass lost before the melting of the anhydrous salt was approximately $12 \%$, corresponding to about $75 \%$ of the total initial water content (16\%) in the hydrous salt. Reactions of this melted salt results in the exothermic peak (D). The products are volatile and thus evaporates causing an endothermic increase in the DSC data (E) and a corresponding mass loss in the TG data. The evaporation is ended by an exothermic reaction (F), 
most probably the formation of tin oxide. Tin oxychlorine species have been proposed to form and evaporate during the oxide formation process [27,28]. Assuming $\mathrm{SnO}_{2}$ as the only product, the deposition efficiency ( $\eta_{\text {eff }}$ ) was $23 \%$ which is almost double that of the tetrachloride salt. A very important difference between the two tin salts is the absence of tin loss at low temperatures $\left(300{ }^{\circ} \mathrm{C}\right.$ ) for $\mathrm{SnCl}_{2} \cdot 2 \mathrm{H}_{2} \mathrm{O}$ while all tin loss for $\mathrm{SnCl}_{4} \cdot 5 \mathrm{H}_{2} \mathrm{O}$ occurs in the temperature range $50-150{ }^{\circ} \mathrm{C}$.

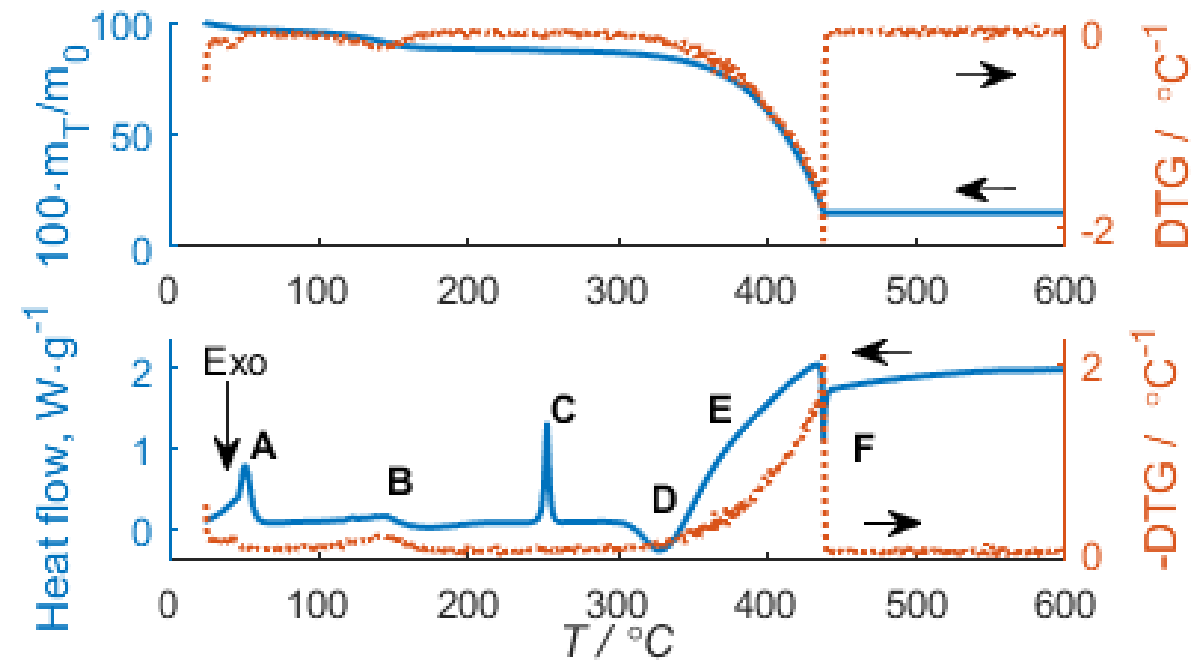

Figure 2. TG (upper) and DSC (lower) data plotted with the differentiated mass loss (DTG) from heating of $\mathrm{SnCl}_{2} \cdot 2 \mathrm{H}_{2} \mathrm{O}$

\section{$\underline{\mathrm{SbCl}_{3}}$}

The TG-DSC data of the antimony salt is presented in Figure 3. The first peak with an onset temperature at slightly above $72{ }^{\circ} \mathrm{C}$ appearing only in the DSC data is the melting of the salt, well in agreement with its literature value of $73.4^{\circ} \mathrm{C}$ [19]. As the second DSC peak has a corresponding peak in the TG/DTG signal, and this loss in mass is initiated by the melting of the salt, this is most probably the evaporation of $\mathrm{SbCl}_{3}$. The abrupt end of the mass loss, and close to zero residual mass (0.7 \%), indicates that close to all $\mathrm{SbCl}_{3}$ evaporated before reaching its boiling point of $220{ }^{\circ} \mathrm{C}$ [19]. This is an issue that should also be investigated to improve the stability and predictability of the electrode preparation process which, to our knowledge, has not been addressed in earlier studies.

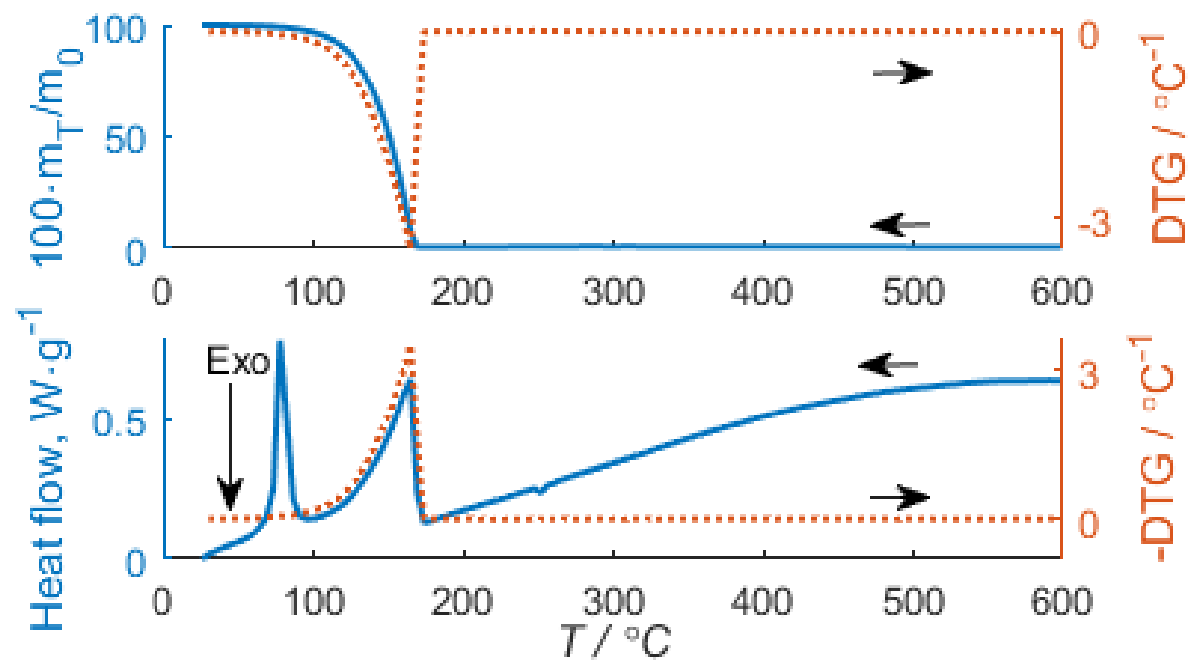

Figure 3. TG (upper) and DSC (lower) data plotted with the differentiated mass loss (DTG) from heating of pure $\mathrm{SbCl}_{3}$ salt 


\section{$\mathrm{NiCl}_{2} \cdot 6 \mathrm{H}_{2} \mathrm{O}$}

In the TG-DSC data of $\mathrm{NiCl}_{2} \cdot 6 \mathrm{H}_{2} \mathrm{O}$ (Figure 4) all peaks up to $400{ }^{\circ} \mathrm{C}$ are present both in the DSC (endothermic) as well as the TG data, indicating that evaporation is occurring. The total mass loss up to this temperature was slightly above $47 \%$, which is well in agreement with the total water content of the salt ( $45.5 \%)$. This therefore means that the crystal water of the hydrated nickel salt evaporates in steps over the temperature range $24-450^{\circ} \mathrm{C}$. The remaining sample after the loss of water is the solid and anhydrous $\mathrm{NiCl}_{2}$ (melting point: $1031^{\circ} \mathrm{C}$ ) [19]. As the temperature is increased beyond $450{ }^{\circ} \mathrm{C}$ mass loss is again seen and a stable residual mass has not been obtained when reaching the end temperature of $600{ }^{\circ} \mathrm{C}$. The reactions occurring in the higher temperature range are most probably the formation of nickel oxide and the evaporation of chlorine. As the reactions were not completed within the temperature range of the experimental run, it is not possible to give any estimation of the deposition efficiency of this salt. However, judging from the data obtained and the high melting temperature of $\mathrm{NiCl}_{2}$, it is concluded that no nickel will evaporate during the electrode preparation process. Nickel salt dissolved in ethanol and n-propanol, respectively, was also heated, both with similar results (see supplementary information).

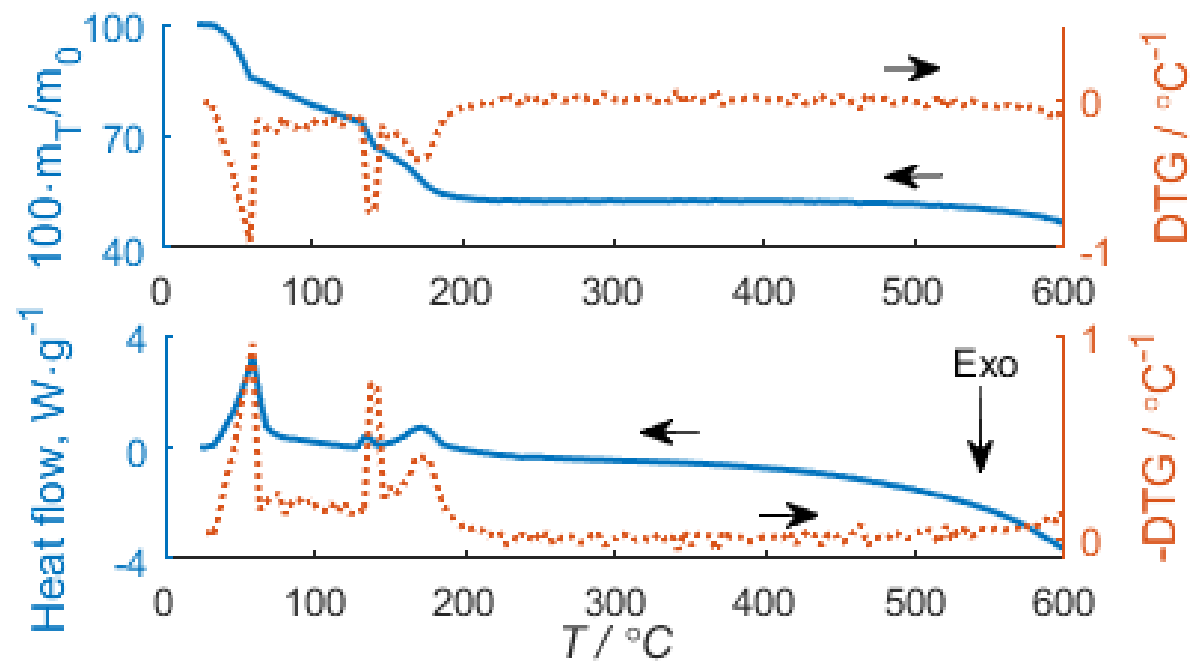

Figure 4. TG (upper) and DSC (lower) data plotted with the differentiated mass loss (DTG) from heating of pure $\mathrm{NiCl}_{2} 6 \mathrm{H}_{2} \mathrm{O}$ salt

TG-DSC of dissolved salts

\section{$\mathrm{SnCl}_{4} \cdot 5 \mathrm{H}_{2} \mathrm{O}$ and $\mathrm{SnCl}_{2} \cdot 2 \mathrm{H}_{2} \underline{\mathrm{O}}$}

Figures 5 and 6 show the heating of the dissolved tin salts in ethanol. Data for the non-dissolved salts from the previous section have been included for comparison. Because of the lower amount of salt the signal is weaker for the dissolved salts but the $\mathrm{SnCl} 4 \cdot 5 \mathrm{H} 2 \mathrm{O}$ dissolved in ethanol mostly follows the same reaction path as the non-dissolved salt (with the addition of the evaporation of solvent). The deposition efficiency was similar in both cases (10 and $12 \%$, respectively) and the only clear difference is a lower temperature at which the weight curve stabilizes for the dissolved salt (approximately 275 versus $410^{\circ} \mathrm{C}$ ). The heating of $\mathrm{SnCl}_{2} \cdot 2 \mathrm{H}_{2} \mathrm{O}$ in ethanol, however, shows a large difference in deposition efficiency compared to that of the non-dissolved salt ( 23 and $54 \%$, respectively). It can also be seen that the decomposition process differs somewhat in the two cases of non-dissolved and dissolved $\mathrm{SnCl}_{2} \cdot 2 \mathrm{H}_{2} \mathrm{O}$. The last large mass loss seen for the non-dissolved salt at $320-438{ }^{\circ} \mathrm{C}$ is not present for the dissolved salt. It seems like the oxide is formed at a lower temperature for the dissolved salt (approximately $310-320$ versus $438^{\circ} \mathrm{C}$ ), considering the 
exothermic peak showing in the DSC data and the stabilization of the mass. A very small mass loss $(0.4 \%)$ occurs after this temperature, this could be the result of the decomposition of remaining organic compounds from the solvent. Solutions of the tin precursors in ethanol and n-propanol with added antimony and nickel salts showed no significant difference from the ethanol solutions without the dopant salts (see supplementary information).

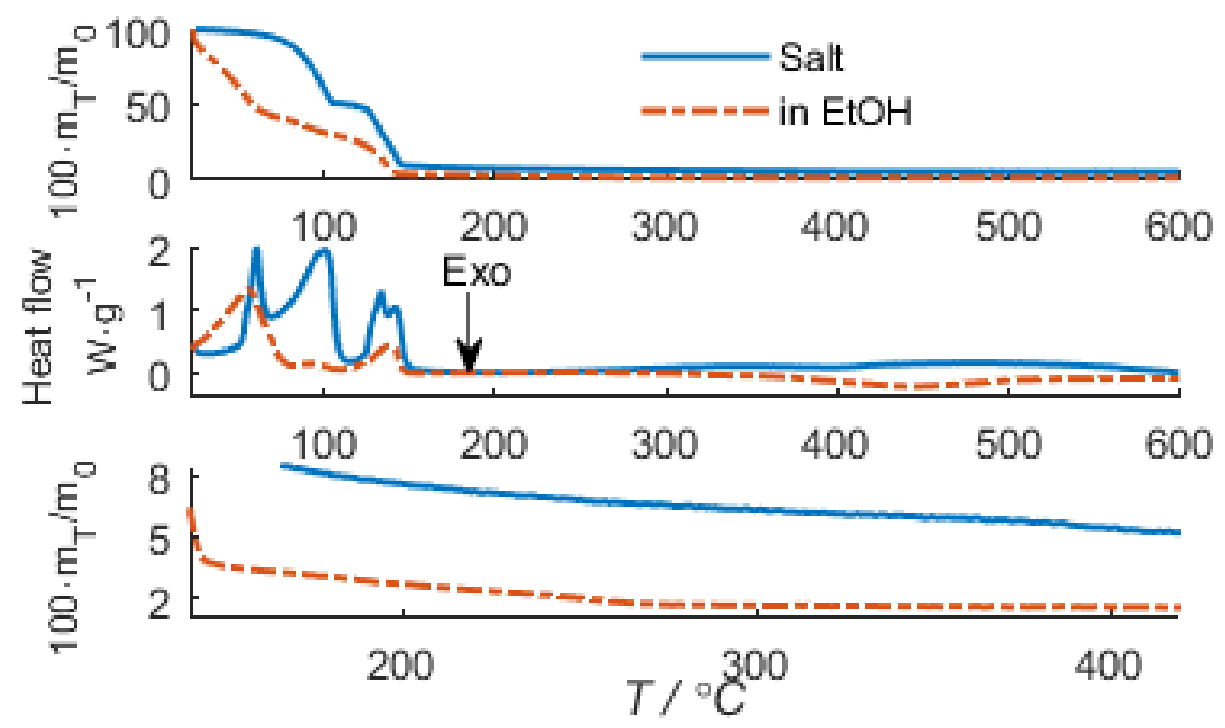

Figure 5. Heating of $1 \mathrm{M} \mathrm{SnCl}_{4} \cdot 5 \mathrm{H}_{2} \mathrm{O}$ dissolved in ethanol shown together with the data from Fig. 1

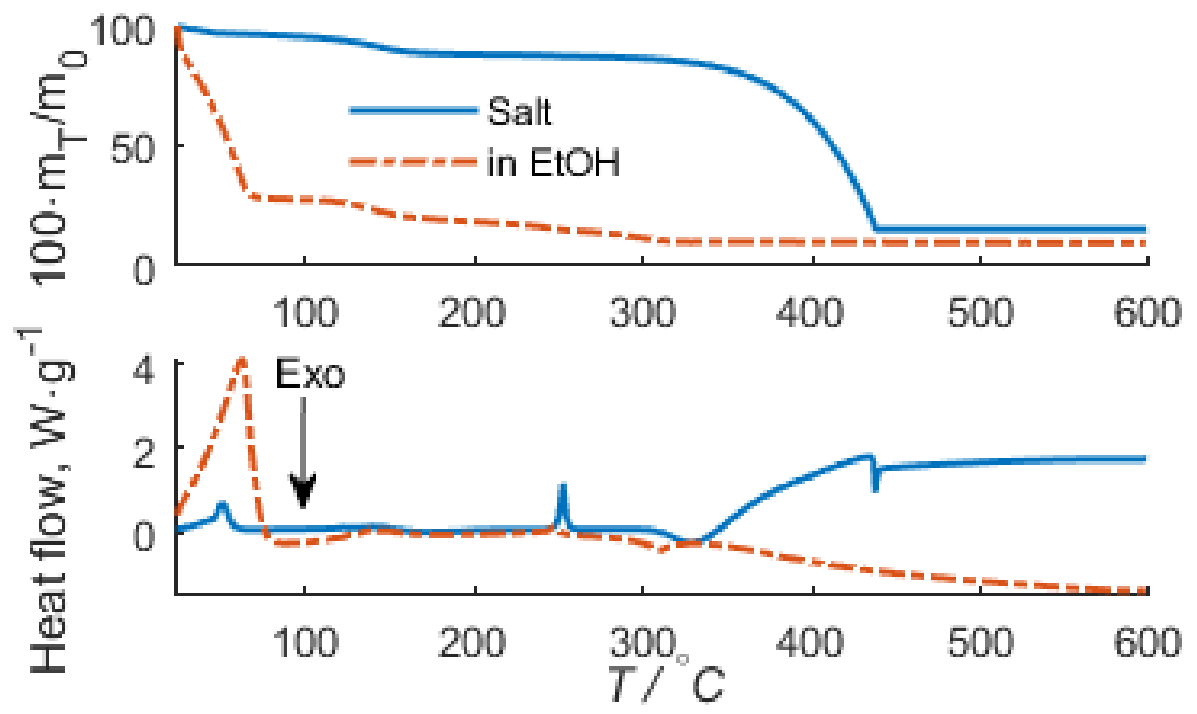

Figure 6. Heating of $1 \mathrm{M} \mathrm{SnCl} 2 \cdot 2 \mathrm{H}_{2} \mathrm{O}$ dissolved in ethanol shown together with the data from Fig. 2

TG-data of $\mathrm{SbCl}_{3}$ dissolved in $\mathrm{n}$-propanol is given together with data of the non-dissolved salt in Figure 7. The residual mass from heating of the ethanol and n-propanol solutions of $\mathrm{SbCl}_{3}$ were 3.1 and $1.2 \%$ of the initial mass, respectively. These are much higher yields compared to the nondissolved salt considering that the mass of antimony salt added was only $\sim 25 \%$ of the initial mass including the solvent.

A possible reason for the increase in yield of the antimony salt is that it reacts with the solvent to form a more stable antimony specie, or with the very small amount of water present in the solvents to form antimony hydroxide. As a support for the latter, precipitations have been observed upon mixing antimony salt solutions with solutions of the hydrated nickel and tin salts. The 
deposition efficiency of antimony (dissolved or not) is however still very low (10\%), which should be considered when used for electrode preparation.

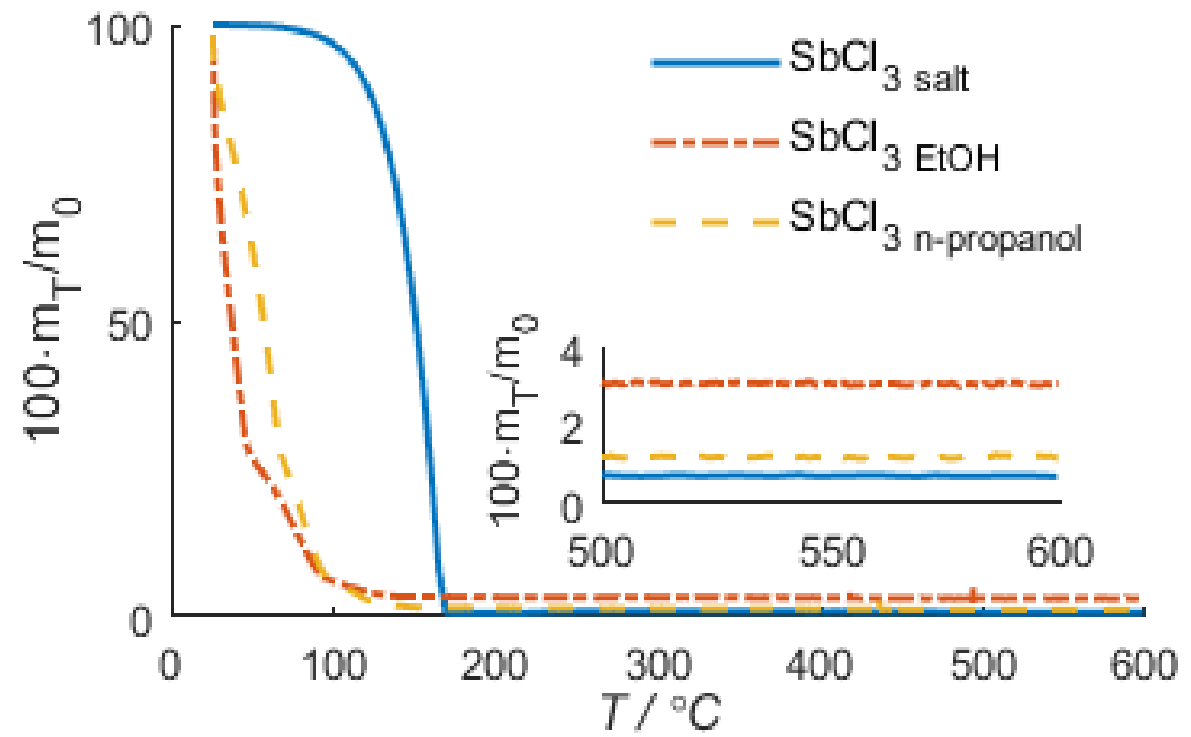

Figure 7. TG-data from heating of $\mathrm{SbCl}_{3}$ as salt and dissolved in EtOH and n-propanol to a concentration of $1 \mathrm{M}$

\section{Heating on titanium substrates}

As the sample volume and size of the sample container can have an effect on the deposition process, trials where a titanium substrate was coated by dripping a known volume of a Sn:Sb:Ni salt solution followed by drying and calcination were made. In this test $n$-butanol (ACS reagent $\geq 99.4 \%$, Sigma-Aldrich) which was not tried in the TG-DSC analysis was included. The drying was made at $80^{\circ} \mathrm{C}$ for 10 minutes and the calcination at $500^{\circ} \mathrm{C}$ for 10 minutes. These trials (presented in Table 1) show similar results to those of of the TG-DSC trials discussed above with the additional indication that $\mathrm{n}$-butanol might increase the deposition efficiency when using $\mathrm{SnCl}_{4} \cdot 5 \mathrm{H}_{2} \mathrm{O}$ as tin source. What should also be noted is that the normalized standard deviations for the tetravalent based coatings are higher than those of the divalent based coatings. These variations could be an effect of the evaporation of $\mathrm{SnCl}_{4}$ at low temperatures $\left(56-147^{\circ} \mathrm{C}\right.$, Figures 1 and 5), probably resulting in loss of tin in both the drying and the calcination step of the heating process.

Table 1. Deposition efficiency average ( $\eta_{\text {eff,avg}}$ ) and normalized standard deviations ( $\sigma / \eta_{\text {eff,avg}}$ ) of three samples per salt and solvent type from heating of $\mathrm{Sn}, \mathrm{Sb}$, and Ni solutions on titanium substrates. Composition in solution (1000:32:4 molar ratios of Sn:Sb:Ni, Sn concentration 1 M).

\begin{tabular}{ccccc}
\hline \multirow{2}{*}{ Solvent } & \multicolumn{2}{c}{$\mathrm{SnCl}_{2} \cdot 2 \mathrm{H}_{2} \mathrm{O}$} & \multicolumn{2}{c}{$\mathrm{SnCl}_{4} \cdot 5 \mathrm{H}_{2} \mathrm{O}$} \\
\cline { 2 - 5 } & $\eta_{\text {eff,avg }} / \%$ & $\sigma / \eta_{\text {eff,avg }}$ & Average $\eta_{\text {eff,avg }} / \%$ & $\sigma / \eta_{\text {eff,avg }}$ \\
\hline Ethanol & 48.2 & 5.6 & 12.4 & 16.7 \\
\hline n-propanol & 48.0 & 5.8 & 8.1 & 13.2 \\
\hline n-butanol & 45.4 & 4.6 & 21.0 & 15.3 \\
\hline
\end{tabular}

\section{Electrode preparation}

Figure 8 shows the increase in loading for the spin coating of titanium substrates with the NATO precursor solutions (drying and calcination after each coated layer) based on the tetravalent and divalent tin salts. The linear fits in Figure 8 yield a 3.3 times faster mass increase for the $\mathrm{SnCl}_{2} \cdot 2 \mathrm{H}_{2} \mathrm{O}$ based coatings than for the $\mathrm{SnCl}_{4} \cdot 5 \mathrm{H}_{2} \mathrm{O}$ based ones. This agrees well with the higher deposition efficiency seen for the divalent tin salt. 


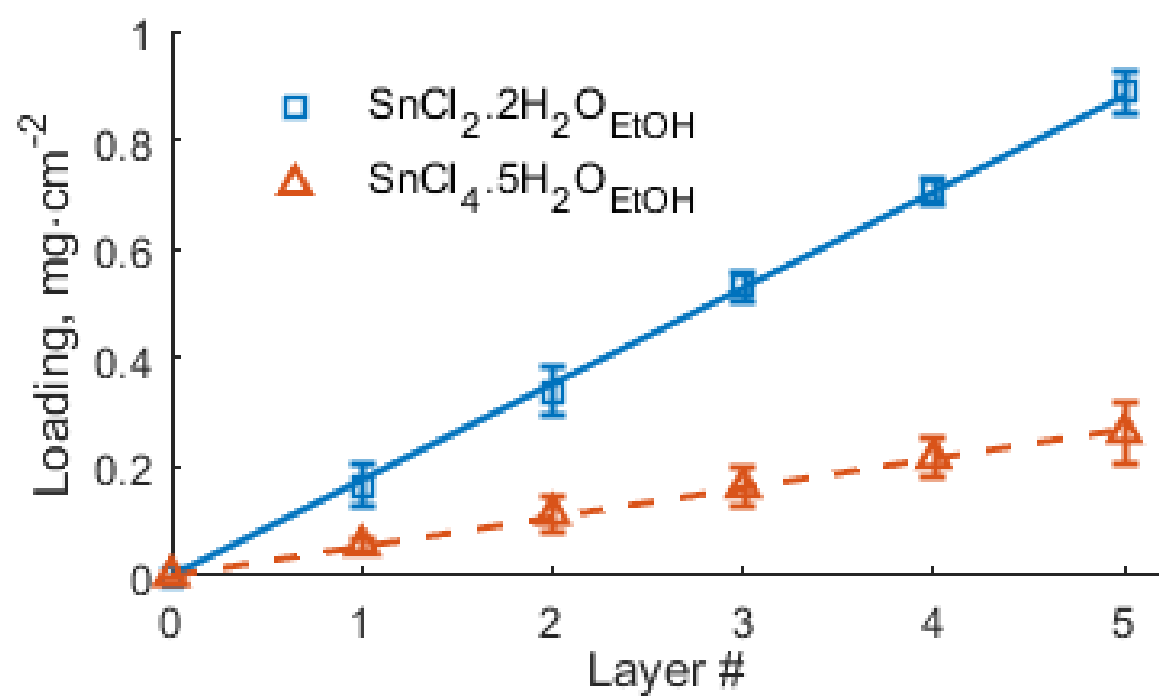

Figure 8. Increase in loading per layer for $\mathrm{SnCl}_{4} \cdot 5 \mathrm{H}_{2} \mathrm{O}$, or $\mathrm{SnCl}_{2} \cdot 2 \mathrm{H}_{2} \mathrm{O}$ based electrode coatings with the precursor composition 1000:16:2 (molar ratios of $\mathrm{Sn}: \mathrm{Sb}: \mathrm{Ni}$ ) in $\mathrm{EtOH}$ (average of three samples, all spin coated)

\section{Surface characterization}

\section{$\underline{\mathrm{XRD}}$}

In Figure 9, XRD data from $\mathrm{SnCl}_{2} \cdot 2 \mathrm{H}_{2} \mathrm{O}$ and $\mathrm{SnCl}_{4} \cdot 5 \mathrm{H}_{2} \mathrm{O}$ based electrodes, both made by spin coating using the precursor composition 1000:16:2 and ethanol as solvent, is presented. Both samples exhibit the rutile tetragonal crystal structure for $\mathrm{SnO}_{2}$ (literature data for $\mathrm{SnO}_{2}$ is seen in the bottom of the figure). No reflections other than those of $\mathrm{SnO}_{2}, \mathrm{Ti}$, and $\mathrm{TiO}_{2}$ were seen. It is very clear from the XRD data that the coating made from the $\mathrm{SnCl}_{2} \cdot 2 \mathrm{H}_{2} \mathrm{O}$ solution is thicker than the one made using the $\mathrm{SnCl}_{4} \cdot 5 \mathrm{H}_{2} \mathrm{O}$ solution as the $\mathrm{SnO}_{2}$ peaks have higher, while the titanium peaks have lower intensity.

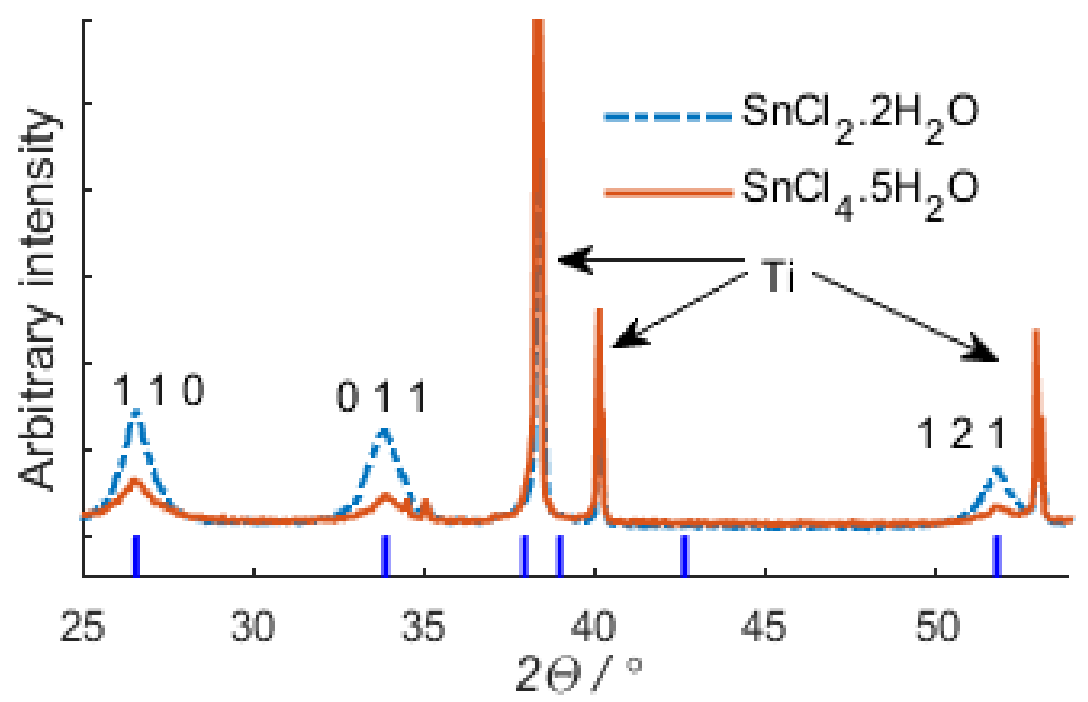

Figure 9. XRD data from measurement on Sn:Sb:Ni oxide coatings on titanium substrates. Identifed $\mathrm{SnO}_{2}$ rutile peaks are indexed

\section{$\underline{\text { SEM }}$}

In Figure 10 SEM micrographs of the two different electrodes presented in Figure 8 and 9 are shown. It can be seen that the surface of the dichloride based electrode is less cracked and smoother than the one prepared using the tetrachloride salt as tin source. 


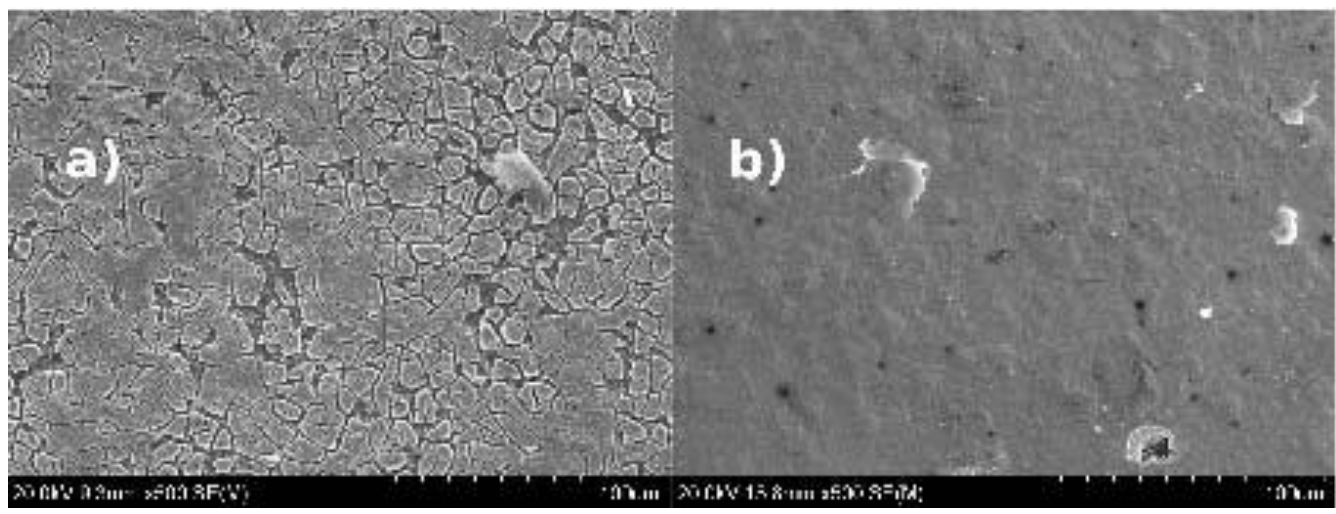

Figure 10. SEM micrographs of a) $\mathrm{SnCl}_{4} \cdot 5 \mathrm{H}_{2} \mathrm{O}$ based and b) $\mathrm{SnCl}_{2} \cdot 2 \mathrm{H}_{2} \mathrm{O}$ based electrode coatings

The difference in surface morphology between the two can be a consequence of several processes. However, the boiling and evaporation of tin tetrachloride probably has a large influence since the calcination is performed almost $400{ }^{\circ} \mathrm{C}$ above its boiling temperature.

\section{$\underline{X R F}$}

XRF measurements were made on the NATO electrodes prepared by spin coating also presented in Figures 8, 9, and 10. Although $\mathrm{Sb}$ could not be determined (probably due to overlapping characteristic X-ray lines), the relative amount of $\mathrm{Ni}$ in the coatings was determined by XRF to a 3.7 times higher concentration in the electrode coating prepared using $\mathrm{SnCl}_{4} \cdot 5 \mathrm{H}_{2} \mathrm{O}$ than in the coating prepared using $\mathrm{SnCl}_{2} \cdot 2 \mathrm{H}_{2} \mathrm{O}$. This agrees with the results presented above from the TG-DSC measurements on the dissolved tin salts where a higher tin loss was observed for the tetravalent salt compared to the divalent salt, meaning that a dopant that does not evaporate will be enriched more when $\mathrm{SnCl}_{4} \cdot 5 \mathrm{H}_{2} \mathrm{O}$ is used as a precursor compared to when using $\mathrm{SnCl}_{2} \cdot 2 \mathrm{H}_{2} \mathrm{O}$.

\section{Electrochemical formation of ozone}

A brief comparison of the ozone formation on $\mathrm{SnCl}_{2} \cdot 2 \mathrm{H}_{2} \mathrm{O}$ and $\mathrm{SnCl}_{4} \cdot 5 \mathrm{H}_{2} \mathrm{O}$ based electrodes $(2 \mathrm{~cm}$ in diameter) was made by galvanostatic electrolysis at different current densities in a batch cell $(13 \mathrm{~mL})$. After each step in current density, the electrolyte $\left(0.1 \mathrm{M} \mathrm{H}_{2} \mathrm{SO}_{4}\right)$ was exchanged. Samples were taken after 2 minutes of electrolysis at each current step and was directly analysed for aqueous ozone concentration using UV-Vis. Results from optical absorption measurements on the samples are presented in Figure 11.

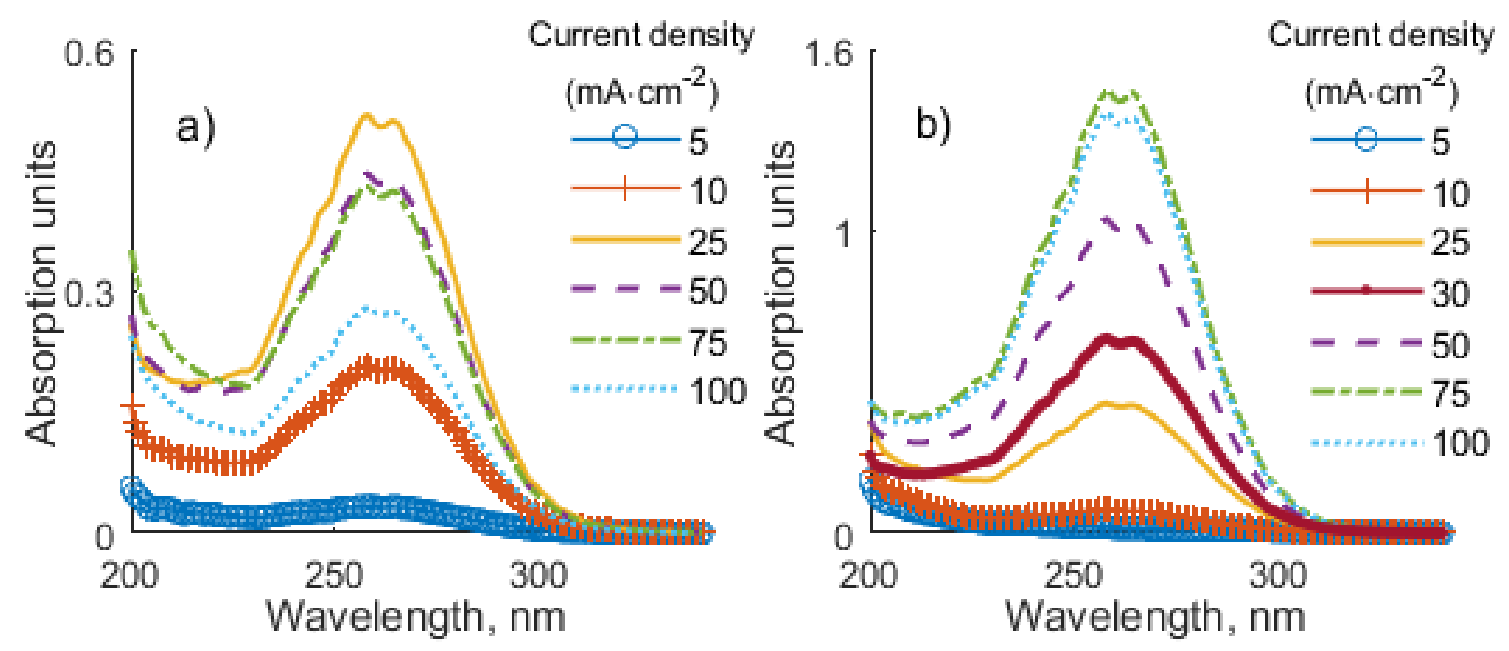

Figure 11. Absorption spectra of samples taken during galvanostatic electrolysis using a) an $\mathrm{SnCl}_{4} \cdot 5 \mathrm{H}_{2} \mathrm{O}$ based electrode, and b) an $\mathrm{SnCl}_{2} \cdot 2 \mathrm{H}_{2} \mathrm{O}$ based electrode 
The tetrachloride based electrode was prepared using a precursor solution with the composition 1000:16:2 in Sn:Sb:Ni and was coated by drip coating as the spin coating yields very thin oxide layers when using the tetrachloride salt. As the results presented above indicates a higher dopant concentration in the tetrachloride based electrodes due to tin evaporation, the concentration of the dichloride based electrode precursor solution was increased 4 times to compensate for this, i.e. in order to obtain similar compositions in the two electrode types. The dichloride based electrode was therefore prepared using a precursor solution with the composition 1000:64:8 and was coated using spin coating. Using the molar absorption coefficient of $3000 \mathrm{~L} \mathrm{~mol}^{-1} \mathrm{~cm}^{-1}$ [29], and the current passed during the time of the experiment, the maximum ozone current efficiencies determined for the two electrodes were both approximately $14 \%$ at 25 and $30 \mathrm{~mA} \mathrm{~cm}^{-2}$ for the tetrachloride and dichloride based electrode, respectively. At current densities higher than these, the current efficiency decreased for both electrodes. It should be noted that these figures were calculated only based on the aqueous ozone, and also that the precursor compositions were not optimized for ozone current efficiency. The electrochemical properties of these electrodes were not the main focus of this study and will be further investigated in future studies.

\section{Importance of preparation route}

The comparison between the two precursors salts $\mathrm{SnCl}_{4} \cdot 5 \mathrm{H}_{2} \mathrm{O}$ and $\mathrm{SnCl}_{2} \cdot 2 \mathrm{H}_{2} \mathrm{O}$ was made with the goal of shedding some light on the problems of using a volatile precursor salt under the preparation conditions previously described rather than to find a replacement salt. Even though the divalent tin salt is more suitable than the tetravalent one under the preparation conditions normally used, it is not an ideal precursor salt as tin loss does occur during the preparation process, causing enrichment of dopants. Three possible ways to overcome the low deposition efficiency could be to change the precursor salts, change the solvent, or to use an alternative synthesis technique such as a hydrothermal process.

A few studies have used water as a solvent instead of alcohol which possibly leads to the formation of non-volatile intermediary species. A higher precursor concentration of dopants would then be necessary in order to end up at similar compositions as when the dopants are enriched due to loss of tin.

Indeed, higher dopant levels in the precursor solution (1000:53:11 molar ratios of $\mathrm{Sn}: \mathrm{Sb}: \mathrm{Ni}$ ) were used by Yang et al. [17] with water as solvent, however no reason for this change is given in the paper. In a later publication [26] they used ethanol as solvent but kept the high dopant levels in the precursor solution. This resulted in a very low current efficiency for ozone formation of $1 \%$, whereas $9.3 \%$ was reached when water was used as solvent. We believe that this may be related to too high dopant concentrations in the coating when ethanol was used as solvent. Christensen et al. [18] recently published a study on ozone forming NATO electrodes where they used water as solvent and by refluxing and autoclaving formed the precursor for their electrode coating. Wang et al. [16] used ammonia and oxalic acid to prepare their precursor, probably forming oxalates [30,31]. These salts should not evaporate [32-34] and thereby the problem of enrichment due to loss of precursors during heating is probably avoided.

\section{Conclusions}

The commonly used preparation procedure for NATO electrodes leads to substantial losses of tin and antimony through evaporation during the drying and heating steps. The nickel salt is not as volatile and will therefore, relatively speaking, be enriched in the electrode coating. Because of the 
evaporation, it is very difficult to control the coating composition and this is a problem from both an environmental as well as an economic perspective. Also, as it has proven difficult to accurately analyse the coating composition, this complicates fundamental studies of the reaction mechanisms on these very interesting electrocatalysts. Exchanging the frequently used tin precursor $\mathrm{SnCl}_{4} \cdot 5 \mathrm{H}_{2} \mathrm{O}$ to the divalent $\mathrm{SnCl}_{2} \cdot 2 \mathrm{H}_{2} \mathrm{O}$ resulted in a significantly better deposition efficiency, 5.5 times higher according to TG-data. The divalent salt will not evaporate in the drying step, but still tin will be lost in the following heating. Further studies for a higher deposition efficiency are needed in order to obtain a preparation procedure where the composition in the resulting oxide coating can be properly controlled. It is also important to find methods for accurate analysis of the composition in the oxide coating, both for total concentrations as well as for how the composition varies with coating depth.

Acknowledgments: The authors would like to thank the Formas research council for financial support and Lina Norberg Samuelsson for her help with the TG-DSC measurements.

\section{References}

[1] K. Arihara, C. Terashima, and A. Fujishima, Journal of the Electrochemical Society, 154 (2007) E71-E75.

[2] P. C. Foller and C. W. Tobias, Journal of The Electrochemical Society 129 (1982) 506-515.

[3] L. M. Da Silva, L. A. De Faria, and J. F. C. Boodts, Electrochimica Acta 48 (2003) 699-709.

[4] A. Kraft, M. Stadelmann, M. Wunsche, and M. Blaschke, Electrochemistry Communications 8 (2006) 883-886.

[5] P. C. Foller and C. W. Tobias, The Journal of Physical Chemistry 85 (1981) 3238-3244.

[6] S. Stucki, H. Baumann, H. J. Christen, and R. Kötz, Journal of Applied Electrochemistry 17 (1987) 773-778.

[7] P. A. Christensen, W. F. Lin, H. Christensen, A. Imkum, J. M. Jin, G. Li, and C. M. Dyson, Ozone: Science \& Engineering 31 (2009) 287-293.

[8] S. A. Cheng and K. Y. Chan, Electrochemical and Solid-State Letters 7 (2004) D4-D6.

[9] Y. H. Wang, S. Cheng, K. Y. Chan, and X. Y. Li, Journal of The Electrochemical Society 152 (2005) D197-D200.

[10] J. B. Parsa, M. Abbasi, and A. Cornell, Journal of The Electrochemical Society 159 (2012) D265-D269.

[11] J. Basiriparsa and M. Abbasi, Journal of Solid State Electrochemistry 16 (2012) 1011-1018.

[12] P. A. Christensen and A. Imkum, Ozone: Science \& Engineering 33 (2011) 389-395.

[13] P. A. Christensen, K. Zakaria, and T. P. Curtis, Ozone: Science \& Engineering 34 (2012) 49-56.

[14] P. A. Christensen, K. Zakaria, H. Christensen, and T. Yonar, Journal of the Electrochemical Society 160 (2013) H405-H413.

[15] H. Shekarchizade and M. K. Amini, International Journal of Electrochemistry 2011 (2011) 113.

[16] Y. H. Wang, Z. Z. Nie, and Y. R. Liang, Advanced Materials Research 734-737 (2013) 21552158.

[17] S. Y. Yang, D. Kim, and H. Park, Environmental Science and Technology 48 (2014) 28772884.

[18] P. A. Christensen, P. S. Attidekou, R. G. Egdell, S. Maneelok, D. A. C. Manning, and R. Palgrave, The Journal of Physical Chemistry C 121 (2017) 1188-1199.

[19] W. M. Haynes, editor, CRC Handbook of Chemistry and Physics, 97th Edition (Internet Version 2017), CRC Press/Taylor \& Francis, Boca Raton, FL., URL http://hbcponline.com/. 
[20] C. Comninellis and G. P. Vercesi, Journal of Applied Electrochemistry 21 (1991) 136-142.

[21] Y. H. Wang, G. Li, Q. Y. Chen, X. Geng, and W. Yan, Journal of Solid State Electrochemistry 17 (2013) 1985-1989.

[22] X. Zhong, B. Yang, X. Zhang, J. Jia, and G. Yi, Particuology 10 (2012) 365-370.

[23] A. Chen, X. Zhu, J. Xi, H. Qin, Z. Ji, and K. Zhu, Journal of Alloys and Compounds 684 (2016) 137-142.

[24] Y. H. Wang, K. Y. Chan, X. Y. Li, and S. K. So, Chemosphere 65 (2006) 1087-1093.

[25] Z. Sun, H. Zhang, X. Wei, R. Du, and X. Hu, Journal of the Electrochemical Society 162 (2015) H590-H596.

[26] S. Y. Yang, W. Choi, and H. Park, ACS Applied Materials \& Interfaces 7 (2015) 1907-1914.

[27] R. Al-Gaashani, S. Radiman, N. Tabet, and A. R. Daud, Materials Science and Engineering: $B$ 177 (2012) 462-470.

[28] E. Horváth, J. Kristóf, H. Nasser, R. L. Frost, A. De Battisti, and Á. Rédey, Applied Surface Science 242 (2005) 13-20.

[29] A. Nemes, I. Fábián, and G. Gordon, Ozone: Science \& Engineering 22 (2000) 287-304.

[30] T. Ahmad, S. Khatoon, and K. Coolahan, Journal of the American Ceramic Society 99 (2016) 1207-1211.

[31] M. E. García-Clavel, M. J. Martinez-Lope, and M. T. Casais-Alvarez, Thermochimica Acta 118 (1987) 123-134.

[32] K. W. Kim, P. S. Cho, J. H. Lee, and S. H. Hong, Journal of Electroceramics 17 (2006) 895898.

[33] N. Deb, S. D. Baruah, N. Sen Sarma, and N. N. Dass, Thermochimica Acta 320 (1998) 53-67.

[34] D. Zhan, C. Cong, K. Diakite, Y. Tao, and K. Zhang, Thermochimica Acta 430 (2005) 101-105.

(C)2017 by the authors; licensee IAPC, Zagreb, Croatia. This article is an open-access article distributed under the terms and conditions of the Creative Commons Attribution license (http://creativecommons.org/licenses/by/4.0/) 